\title{
Impact of seasons on an individual's chronotype: current perspectives
}

This article was published in the following Dove Press journal:

Nature and Science of Sleep

\author{
Nyambura Shawa' \\ Dale E Rae ${ }^{2}$ \\ Laura C Roden' \\ 'Department of Molecular and Cell \\ Biology, University of Cape Town, \\ Cape Town, South Africa; ${ }^{2}$ Health \\ through Physical Activity, Lifestyle and \\ Sport Research Centre, Department \\ of Human Biology, Faculty of Health \\ Sciences, University of Cape Town, \\ Cape Town, South Africa
}

Correspondence: Laura C Roden Department of Molecular and Cell Biology, University of Cape Town, Private Bag Rondebosch, Cape Town 770I, South Africa

Email laura.roden@uct.ac.za

\begin{abstract}
Diurnal preference, or chronotype, determined partly by genetics and modified by age, activity, and the environment, defines the time of day at which one feels at his/her best, when one feels sleepy, and when one would prefer to start his/her day. Chronotype affects the phase relationship of an individual's circadian clock with the environment such that morning types have earlier-phased circadian rhythms than evening types. The phases of circadian rhythms are synchronized to the environment on a daily basis, undergoing minor adjustments of phase each day. Light is the most potent time cue for phase-shifting circadian rhythms, but the timing and amount of solar irradiation vary dynamically with season, especially with increasing distance from the equator. There is evidence that chronotype is modified by seasonal change, most likely due to the changes in the light environment, but interindividual differences in photoperiod responsiveness mean that some people are more affected than others. Differences in circadian light sensitivity due to endogenous biological reasons and/or previous light history are responsible for the natural variation in photoperiod responsiveness. Modern lifestyles that include access to artificial light at night, temperature-controlled environments, and spending much less time outdoors offer a buffer to the environmental changes of the seasons and may contribute to humans becoming less responsive to seasons.
\end{abstract}

Keywords: diurnal preference, photoperiod, latitude, circadian photoreception

\section{Chronotype}

Chronotype is often thought of simply as one's preference to wake early or late, related to one's ability to stay up late at night. However, underpinning these preferences are temporal differences in physiology based on an individual's circadian biology and the phase angle of entrainment to the external environment. ${ }^{1}$ This manifests as different phases of temporal variations relative to environmental or societal time in not only sleeping patterns, but also physical performance, hormone levels, core body temperature, cognitive faculties and eating behavior. ${ }^{2-4}$ Thus chronotypes reflect differences in the phases of "internal" time relative to external time, rather than just self-reported preference for timing of activity and sleep. Chronotype has a genetic basis, ${ }^{5-8}$ and is modified by sex, development, physical activity, and the environment. ${ }^{4,9-12}$ The relevance of chronotype is apparent when we consider the current increase in the prevalence of non-communicable diseases as there is evidence to suggest that those with an evening preference are more at risk of developing obesity and type 2 diabetes mellitus. ${ }^{13-15}$ Chronotype is also an important consideration when it comes to physical or mental performance, since the timing of events or scheduling of work, school, or 
examinations may favor or affect certain chronotypes. ${ }^{16,17}$ Depressive symptoms and mood disorders have also been reported to associate with chronotype, ${ }^{18-21}$ and thus investigating modifiers of chronotype is of interest.

\section{How is chronotype assessed?}

Although chronotype is most easily assessed subjectively via questionnaires, the questionnaires in common use have been validated through biological measures. In 1976, Horne and Ostberg, ${ }^{2}$ in a landmark publication investigating chronotype and phase of oral temperature, designed and evaluated a questionnaire called the Morningness-Eveningness Questionnaire (MEQ). The MEQ was based on a previous Swedish-language MEQ. It has 19 items, which are of Likert type, and when tallied give a score ranging from 16 to 86 that places individuals into one of the following five categories: definite evening type, moderate evening type, neither type, moderate morning type, and definite morning type. The MEQ was validated using oral temperature taken at approximately 30-minute intervals from the time of awakening until sleep time. ${ }^{2}$ They observed that the individuals who scored as morning types had earlier peaks in oral temperatures than those who scored as evening types. They also observed earlier rising and sleep times in the morning types than in the evening types. The neither types were somewhere in between both in terms of the time of peak oral temperature and rising and sleep times. ${ }^{2}$ There is also a reduced version that has been validated, which is quicker to complete, reliable, and shows adequate inter-item correlation and reliability. ${ }^{22}$

The Composite Scale of Morningness (CSM) came about from the extraction of questions from three morningness questionnaires. ${ }^{23}$ It is made up of 13 questions with Likerttype responses, which give an indication of individual preference for timing of different activities and the ease of waking up in the morning. It includes items from the MEQ and from the diurnal-type scale. ${ }^{24}$ The diurnal-type scale was designed to be used to determine preference for timing of activity in spite of irregular work schedules; ${ }^{24}$ however, it has been used less frequently than the other instruments. The CSM total score ranges from 13 to 55 with higher scores indicating morningness. The scale ultimately places an individual into one of the following three categories: evening type, intermediate type, and morning type. The CSM score has good psychometric properties, remains stable over time, and does not change when individuals are in engaged in night- or rotating-shift work. ${ }^{1}$

Another widely used instrument to assess chronotype is the Munich ChronoType Questionnaire (MCTQ) that assesses an individual's phase of entrainment with simple questions. ${ }^{25}$ The questions are about sleep and activity times including when one goes to bed, how long one needs to fall asleep, and when one wakes up. For both work and free days, the same set of questions is asked. This questionnaire has been validated, with highly significant correlations, by sleep logs and actimetry and correlates well to biochemical rhythms such as melatonin and cortisol. ${ }^{26}$ In addition, the phase of entrainment determined by the MCTQ correlates well with the score produced by the MEQ. ${ }^{27}$

\section{The circadian oscillator and chronotype}

Chronotype is influenced by genetics due to the molecular basis of innate circadian rhythm generation. The circadian oscillator consists of interconnected transcription-translation feedback loops that involve several gene products and produces robust rhythms in various outputs with a period of close to, but not exactly, 24 hours. ${ }^{28}$ These feedback loops operate like clockwork cogs in almost every cell of the body, and the rate of the oscillator is modified as required due to environmental conditions or activity levels, to maintain rhythms of close to 24 hours. The circadian oscillator generates various output rhythms with different phases and specific phase relationships to one another. ${ }^{28}$ For example, the peak of the pineal hormone melatonin usually precedes the minimum in core body temperature by $1-2$ hours. ${ }^{29}$ Both melatonin and core body temperature are used as phase markers of the endogenous circadian clock. ${ }^{29,30}$

The circadian clock can be synchronized to external time via several time cues, or zeitgebers (time-givers), the most powerful being light. ${ }^{31}$ Synchronization is achieved through zeitgeber-induced phase shifting of circadian rhythms at the molecular level. ${ }^{32}$ There is a master circadian oscillator in the suprachiasmatic nuclei (SCN) in the hypothalamus, which provides both environmental and biological timing to the rest of the body. ${ }^{33-35}$ Light enters the eyes and is perceived by the retina which, apart from containing rod and cone photoreceptors, contains a small subset of intrinsically photosensitive retinal ganglion cells that project to the $\mathrm{SCN} .^{36}$ These cells express the photopigment melanopsin ${ }^{37}$ and are responsible for the transmission of photic cues via the retinohypothalamic tract to the SCN ${ }^{38}$ Melanopsin is most sensitive to light with a wavelength of $480 \mathrm{~nm},{ }^{39,40}$ which corresponds with the previously reported wavelengths most effective in circadian phase shifting and melatonin suppression. ${ }^{41,42}$ These signals align the circadian oscillator to the external 24 hours light-dark cycle by causing delays or advances in the phase of rhythms. The relationship between the timing of a light pulse 
and the phase shift it elicits is represented by a phase response curve (PRC), and the human PRC to light is similar to that of most diurnal species. ${ }^{43}$ Light is most effective at causing these shifts in phase during the night, with light signals early in the night (evening) causing delays in rhythms to a later hour, and signals late in the night (in the early hours of the morning) producing phase advances to an earlier hour. ${ }^{44,45}$ In response to light signaling, the SCN sends synchronizing neural and hormonal signals to the clocks in the rest of the body. ${ }^{35}$ The signals synchronize the rhythms present in tissues throughout the body such that they attain a specific phase relationship with each other and the external environment. ${ }^{32}$

As there is genetic variation in humans, there are interindividual differences in the period of innate circadian rhythm as assessed by outputs such as core body temperature or melatonin rhythm. It has been found that the endogenous circadian period measured in constant routine, where periodic environmental time cues have been removed in order to assess the contribution of the circadian oscillator to the observed rhythmicity, ${ }^{46}$ is shorter ${ }^{47}$ and the timing of the core body temperature peak is earlier ${ }^{48}$ in morning-type people than those with a preference for evening activity. Individuals with shorter periods will have earlier circadian phases of specific rhythms such as core body temperature or melatonin secretion within their sleep-wake cycles and relative to the light-dark cycle, whereas those with longer periods will have phases later within the sleep-wake cycle. Duffy et al found that morning types wake significantly later within their circadian cycle than do evening types. ${ }^{49}$ Thus, morning types had a longer interval between the timing of their circadian peaks of core body temperature and plasma melatonin and their usual wake time. The correlation between intrinsic circadian period, chronotype, and habitual awakening time suggest a circadian mechanism underlying morningness-eveningness. ${ }^{47}$

\section{Seasons, photoperiod, and circadian light sensitivity}

The most obvious and reliable feature of seasons is the change in daylength or photoperiod with shorter photoperiods during winter months and longer photoperiods during summer. ${ }^{50}$ The differences are most dramatic with increasing distance from the equator (latitude) and are most extreme inside the Arctic and Antarctic circles, where the sun is entirely absent for part of winter, and always present during parts of the summer. ${ }^{50}$ The duration of daily exposure to bright light (>1000 lux) is longer in summer than in winter and, as one might expect, has been shown to alter many circadian-related biological processes. For example, Hébert et al noted that the phase of the sleep-wake cycle was earlier in summer than in winter for people living at $45^{\circ} 31^{\prime} \mathrm{N} .{ }^{51}$ Wehr found that sleep duration was longer in winter than in summer photoperiods in a small study involving eight male participants and that the longer sleep was associated with longer duration of melatonin secretion. ${ }^{52}$ Wehr et al explored the photoperiod responsiveness in a group of 15 adults (one female), measuring melatonin, prolactin, cortisol, growth hormone, and core body temperature in long and short photoperiods in the laboratory. ${ }^{53}$ Although there was variability in responsiveness, sleep was extended in short photoperiods in most participants (12 of 15). The electroencephalogram-measured sleep showed a bimodal pattern with a period of quiet wakefulness in the longer nights. ${ }^{53}$ There was also some variability in melatonin photoperiod responsiveness, with some participants having increased sleep duration without altering melatonin secretion and others displaying increased duration of melatonin secretion without an increase in sleep duration. Interestingly, the participants felt less fatigued, happier, and more energetic in the shorter photoperiods. ${ }^{53}$

In experiments carried out in natural seasons at $50^{\circ} \mathrm{N}$, studies by Illnerová's group showed that melatonin secretion was of shorter duration and that off-set was phase-advanced in summer compared to winter in adolescents and adults. ${ }^{54,55}$ However, when Illnerova et al investigated the time taken to adjust to a change in photoperiod in an experiment carried out during natural summer and a simulated winter photoperiod at $50^{\circ} \mathrm{N}$, they found that the melatonin secretion was longer with the on-set phased earlier in the shorter photoperiod, and the adjustment happened on the first night of exposure to a short photoperiod. ${ }^{56}$ They suggested that the advance observed in the shorter photoperiod may have been due to the removal of phase-delaying evening light. ${ }^{56}$ Peak plasma melatonin concentrations measured in a group of Swedish office workers were lower in summer than in winter, but no seasonal difference was detected in the timing of the melatonin peak. ${ }^{57}$ In a year-round study of field workers in Antarctica $\left(77^{\circ} \mathrm{S}\right)$ who undertook rotating shift-work, the sleep-wake rhythm was set by their work schedule, but the phase of plasma melatonin and core body temperature rhythms were affected by the photoperiod, with phase advances in summer and delays in winter. ${ }^{58}$ One possible explanation for the observation of a photoperiod circadian phase association in the Antarctic study but not the Swedish study may be that the participants in the Antarctic study worked outdoors and were thus exposed to the changing environmental conditions, whereas the indoor work environment conditions of the Swedish office workers would not change as dramatically. Taken together, it appears 
that exposure to natural light with the change in seasons has an effect on the circadian physiology of an individual.

Besides light abundance, the spectral composition of light is also important since our circadian system is more sensitive to shorter wavelength (blue) light than longer wavelength light, ${ }^{39-42}$ which has been shown to vary with seasons. ${ }^{57,59}$ A UK-based study using wrist-worn light meters observed that not only was total light exposure lower in winter than in summer, but also daily blue light exposure in summer was almost double than that in winter. ${ }^{59}$ Similar findings were made in Sweden ${ }^{57}$ with wrist- and chest-worn light sensors. The seasonal differences in abundance and composition of light exposure were most pronounced during the evening hours, ${ }^{57,59}$ when light exposure would be expected to induce phase delays in the circadian system. ${ }^{31}$ These differences in light exposure would affect the phase of entrainment of the circadian clock differently in summer compared to winter and thus potentially affect chronotype in a seasonal manner.

In addition to changes in the light environment with seasons, inherent differences in light sensitivity, due to environment or genetic variations, may also alter phase responsiveness and thus affect chronotype. Eye color and photoresponsiveness of the melanopsin-signaling system have been shown to alter circadian light sensitivity ${ }^{60}$ and associate with chronotype. ${ }^{61}$ Light-induced suppression of melatonin was greater in Caucasians with light-colored eyes than in Asians with dark-colored eyes, ${ }^{60}$ indicating that differences in circadian light sensitivity are caused in part by differences in eye pigmentation. A correlation was observed between the melanopsin-mediated pupillary response to blue light and sleep timing based on the MCTQ, sleep diary, and actigraphy, where those with later mid-points of sleep were the most responsive to blue light. ${ }^{61}$ Although no causal relationship was explored in the study, it seems that circadian light sensitivity is associated with habitual sleep timing and chronotype.

Sensitivity to light has been demonstrated to have a seasonal basis in animals and humans, especially those who suffer from Seasonal Affective Disorder (SAD) or winter depression. ${ }^{62-64}$ Studies have demonstrated that prior light exposure modifies the sensitivity of the human circadian system to light, ${ }^{65,66}$ which partly accounts for seasonal differences in circadian light sensitivity. ${ }^{67}$ For example, Hébert et al demonstrated that the magnitude of the suppression of melatonin was greater in individuals exposed to dim light prior to a saturating light pulse than those with prior exposure to bright light. ${ }^{65}$ It was later demonstrated that this light history-altered sensitivity affected the phase shifting response of the clock to light. ${ }^{68}$ In a study carried out in northern Japan, where the photoperiod is approximately 15 hours in summer and 9 hours in winter, Higuchi et al found that the magnitude of light-induced melatonin suppression was greater in winter than in summer. ${ }^{67}$

Intrinsic circadian period (tau) may also have a bearing on the timing of circadian light sensitivity, that is, the phase responsiveness to light. Smith et al reported a significantly shorter tau in African Americans in comparison to Caucasians and Asians. ${ }^{69}$ They also reported that when African American participants were exposed to a phase-delaying protocol that included an evening light pulse, they had smaller phase delays in comparison to Caucasian participants. Therefore, this shorter tau may result in less sensitivity to phase-delaying evening light of later sunsets typical of latitudes more than $23.5^{\circ}$ away from the equator. It has been proposed that selection for a longer circadian period after early humans migrated out of Africa was adaptive for entrainment to the greater photoperiod changes with seasons at higher latitudes. ${ }^{70}$

Some gene variants have been found that modulate circadian light sensitivity and affect sleep and or seasonal depression. A length polymorphism in a circadian-clock associated gene, PERIOD3 (PER3), has been associated with chronotype ${ }^{71,72}$ and blue-light sensitivity for melatonin suppression. ${ }^{73}$ Those who are homozygous for the shorter $P E R 3^{4}$ allele are more likely to be evening types ${ }^{71}$ and are less sensitive to end-of-day blue light-induced suppression of melatonin ${ }^{73}$ than those who are homozygous for the longer $P E R 3^{5}$ allele associated with morningness. ${ }^{72}$ This is in apparent contradiction with the hypothesis that morning types who tend to have a shorter tau are less sensitive to the phasedelaying effects of evening light. ${ }^{69,70}$ However, it should be noted that in the study by Chellappa et a ${ }^{73}$ participants with extreme chronotypes were excluded and tau was not assessed, and the association of the $P E R 3^{5}$ allele with morningness has not been found in all studies. ${ }^{74-76}$ Polymorphisms in the clock-associated PER2 gene have been found that account for variation in the magnitude of light-induced melatonin suppression. ${ }^{77}$ Interestingly, the ancestral PER2 haplotype (a particular combination of the single nucleotide polymorphism [SNP] rs4663302, rs147573126, rs190386281, rs142175638, rs11894535, and rs934945 variants within the PER2 gene) conferred low light sensitivity and was more frequently found inside Africa than outside Africa, and there was more diversity in PER2 variants in non-African populations than in African populations. ${ }^{77}$ Cruciani et al analyzed variations in a $7.7 \mathrm{~kb}$ region of the $P E R 2$ locus in individuals from five continents. ${ }^{78}$ While they found no evidence of 
latitudinal selection at the locus, they did find distinct genetic differences between Africans and non-Africans and selection signals suggesting strong geographical natural selection. The interpopulation genetic differentiation suggested that the differentiation of the PER2 locus and selection occurred after the out-of-Africa migration to areas with greater seasonal variation in photoperiod. ${ }^{78}$

A variant (rs2675703; P10L) in the melanopsin gene (OPN4) has been found at a higher frequency in patients with SAD. ${ }^{79}$ In healthy participants, the same variant was associated with earlier bedtimes on shorter days and later bedtimes on longer days.$^{80}$ Participants who were homozygous for the P10L TT variant showed photoperiod responsiveness in terms of bedtimes and chronotype: they had earlier bedtimes and greater morning preferences when assessed in short days, and later bedtimes and more eveningness when assessed in long days. ${ }^{80}$ None of the other P10L genotypes showed the photoperiod-dependent change in chronotype..$^{80}$ Lee et al demonstrated that the rs 1079610 SNP in OPN4, previously functionally associated with pupillary light reflex and light sensitivity, ${ }^{81}$ was associated with habitual sleep timing in Japanese university students. ${ }^{82}$ While students of all three genotypes of this SNP had relatively low MEQ scores, those who were homozygous $\mathrm{CC}$ had significantly later bedtimes and midpoints of sleep. ${ }^{82}$

These and other genetic or ancestry-specific differences affecting circadian light perception may account for interindividual differences in responsiveness to changes in photoperiod. However, it seems unlikely that within populations there are photoperiod-sensitive and -insensitive people. ${ }^{83}$ It is more likely, as proposed by Roenneberg, that some people are more sensitive while others are less sensitive to photoperiod. ${ }^{84}$ Further modulating our responsiveness is the variation in individual's exposure to the outdoors and seasons. As human populations become more industrialized and live increasingly in urban environments with artificial light at night, heating and cooling in homes and work spaces, combined with increasing time spent indoors and fewer outdoor occupations, we are less exposed to natural seasons. Seasonal birth rhythms have dampened, losing their correlation first with photoperiod and then with ambient temperature due to industrialization. ${ }^{85}$ Sleep timing and duration in pre-industrial populations, such as the Southern African Sān people, show seasonal variation with shorter duration and delayed sleep timing in summer. ${ }^{86}$ Access to electricity, and thus light at night, resulted in delayed sleep timing in an African community undergoing transition to urbanization relative to a neighboring village without electricity. ${ }^{87}$ Both communities in the Beale et al study had exposure to bright sunlight in the mornings and during the day. ${ }^{87}$ Industrialized populations with reduced early morning natural light exposure and artificial light at night have later and shorter sleep durations. ${ }^{88}$ When exposed to the natural light-dark cycle, for example when camping, participants showed photoperiod responsiveness with earlier sleep onset and longer sleep in winter than in summer. ${ }^{89}$ Thus, natural and artificial factors may modulate chronotype and the seasonal effects on chronotype assessed in populations.

\section{Chronotype and latitude}

As seasonal variation in photoperiod is greatest further from the equator, one might expect circadian entrainment and chronotype to be affected by latitude. Leocadio-Miguel et al assessed chronotype using the MEQ in a countrywide sample of the Brazilian population $(n=12,884) .{ }^{90}$ Information concerning gender, city of residence, age, and work/study routines was also collected from participants. The landmass of Brazil ranges from latitude $05^{\circ} 16^{\prime} \mathrm{N}$ to $33^{\circ} 45^{\prime} \mathrm{S}$ and longitude $34^{\circ} 47^{\prime} \mathrm{W}$ to $73^{\circ} 59^{\prime} \mathrm{W}$, but most of the population live in the same time zone with the highest density at, or around, the coast. The study chose participants living between $0^{\circ}$ and $32^{\circ} 33^{\prime} \mathrm{S}$ and a longitude range from $34^{\circ} 50^{\prime} \mathrm{W}$ to $57^{\circ} 05^{\prime} \mathrm{W}$, which is the time zone UTC/GMT -3 . The season at the time participants took part was recorded and was accounted for as a cofactor in the analyses. The authors reported that the annual average solar irradiation exerts a systematic effect on MEQ score even after controlling for age, longitude, and sex. They found that the further away the population is from the equator, ie, where they would experience lower mean irradiation levels, the more significant the shift of chronotype distribution toward later chronotypes. ${ }^{90}$ They attributed this in part to more light in the evenings in summer as the latitude increases, resulting in light exposure occurring when the human phase response to light is sensitive to delays. Concomitantly, they reasoned that the later sunrise during winter as the latitude increases and low levels of solar irradiance reduce exposure to light during a phase sensitive to phase advances.

An earlier study ${ }^{91}$ also reported an increased tendency toward late chronotype at higher latitudes. In a comparison between cities that are approximately $4.5^{\circ}$ apart (Syktyvkar: $61.4^{\circ} \mathrm{N}$; Inta: $66.0^{\circ} \mathrm{N}$ ), a significant increase in evening typology among 13- to 17-year-olds was observed in the city of Inta. Randler carried out an investigation of chronotype in adolescents in 17 countries, which revealed a significant association with both latitude and longitude. ${ }^{92}$ Participants were divided into tropics, subtropics, and temperate zones; 
individuals in the subtropics were the latest chronotypes while individuals in the tropics were the earliest chronotypes. The authors also observed that within the central Europe time zone, there was more morning orientation toward the North and the East. ${ }^{92}$ In a study conducted in a region of northern Russia ranging in latitude from $59.5^{\circ} \mathrm{N}$ to $67.6^{\circ} \mathrm{N}$, it was observed that each $8^{\circ}$ increment in latitude resulted in the midpoint of sleep being delayed by 1 hour..$^{93}$ Latitude accounted for almost $42 \%$ of variability in chronotype and was most marked in those living in rural rather than urban environments. $^{93}$

\section{Photoperiod at birth, season, and chronotype}

There is a hypothesis which proposes that the duration of daylight following birth sets the internal clock and this is the basis of the effect of season-of-birth on chronotype in adulthood. ${ }^{94.95}$ An imprinting-like phenomenon may occur during a "sensitive phase" during the 3 months after birth, a significant period of time during which an individual's sleep-wake cycle is being developed, and the photoperiods in the weeks following birth have an influence on chronotype. ${ }^{94}$ Individuals born during long or lengthening photoperiods (summer or spring) would set their internal clock with longer days in comparison to those born during the shorter or shortening photoperiods characteristic of winter or autumn.

A study of adolescents born between July 1993 and July 1999 in adjacent German regions at $49^{\circ} \mathrm{N}$ took photoperiodat-birth (PAB) into consideration when assessing chronotype using the CSM. ${ }^{96}$ Individuals born when photoperiod was increasing (spring) were more evening-oriented and had later midpoints of sleep than those born when photoperiod was decreasing (autumn), who were more morning-oriented. As these differences were detectable only when comparing increasing vs decreasing photoperiod groups, and when a quadratic or cosine function was applied to the data, the authors suggested that this implied that the effect of PAB on chronotype was small. ${ }^{96}$ However, it is possible that grouping individuals by season of birth may be masking the effect of PAB on chronotype as photoperiod varies even within a season.

Mongrain et al used the MEQ to determine chronotype in 1,591 (1102 women) young adults aged 17-35 years in Montreal, Canada $\left(45^{\circ} 31^{\prime} \mathrm{N}\right)$ with data collection taking place over a period of 4 years. ${ }^{95}$ Photoperiod for each individual's date-of-birth was estimated using photoperiod for Montreal City, and four categories of photoperiod length $(8-10,10-12,12-14,14-16$ hour) were used in the analyses. ${ }^{95}$ While the exact place of birth was not asked for in the questionnaire, approximately $95 \%$ of participants were from the province of Quebec where the study was conducted. Participants born during autumn with a photoperiod of 8-10 hour had higher MEQ scores (ie, tended more toward morningness) than participants born during spring with either 12-14 hour or 14-16 hour photoperiods. Interestingly the MEQ scores of participants born in summer or winter were not different. ${ }^{95}$ A limitation in this study is that season during which the questionnaire was completed was not taken into consideration.

One study compared the association between season-ofbirth and chronotype between a population in the southern hemisphere (Rockhampton, Australia, 22 ${ }^{\circ} \mathrm{S} ; \mathrm{n}=757$ ) with one in the northern hemisphere (Bologna, Italy, $41^{\circ} \mathrm{N}$; $\mathrm{n}=997) .{ }^{94} \mathrm{CSM}$ scores were higher in Australian participants in comparison to Italian participants, and females reported higher CSM scores in both Italy and Australia. ${ }^{94}$ Despite the difference in magnitude of CSM scores between the two study sites, which may be due in part to latitude or cultural differences (eg, Italians take a mid-afternoon rest, or "risposo," which is not common in Australia), the association of season-of-birth and chronotype was similar. In the Northern hemisphere, morningness was linked with winter and autumn births (September to March), while eveningness was more frequent in those born in spring and summer (March to September). In the Southern hemisphere, the pattern was similar as those born from March to September (winter and autumn) were more frequently morning types, whereas those born from September to March (spring and summer) were linked with eveningness. ${ }^{94}$ Three limitations to this study, however, are that there was a difference in latitude between the northern and southern hemisphere cities, city of birth was not recorded and thus the season-of-birth was assumed, and the time of year the CSM was completed was not taken into consideration. However, similar observations were made in young Italian and Spanish populations: 899 Italian (651 female) and 685 Spanish (518 female), age ranged from 18-34 years. ${ }^{97}$ Males born between October and March (colder months) were more morning-orientated than those born between April and September (warmer months); this was not found among female participants.

Collectively these studies suggest at least some role for PAB in determining adolescent and young adult chronotypes. It seems that latitude is responsible for part of the variation in effect size. For example, Borisenkov et al measured chronotype in 1,172 children and teenagers (609 girls) aged 11-18 years from nine locations, within northern Russia, ranging 
in latitude from $59.5^{\circ} \mathrm{N}$ to $67.6^{\circ} \mathrm{N} .{ }^{93}$ They observed that individuals born north of the Arctic circle $66.5^{\circ} \mathrm{N}$ at polar day (summer solstice, sunrise: 00:00 hours) or polar night (winter solstice, sunrise: 12:00 hours) had later chronotypes than individuals born in other seasons. ${ }^{93}$ They suggested that time of sunrise, sunset and daylength at birth had a significant impact on chronotype, ${ }^{93}$ factors all determined by both latitude and longitude which have also been shown to affect chronotype..$^{90,98,99}$

\section{Chronotype and seasonal daylight saving} Many countries in higher latitudes adopt a daylightsaving time (DST), where the societal clock is adjusted by 1 hour, advancing in spring and delaying in autumn. Some studies have assessed the impact of DST on clock entrainment. ${ }^{100,101}$ In a large study of 55,000 participants from Germany, Italy, Switzerland, France, Slovakia, the Netherlands, and Luxembourg, Kantermann et al found chronotype-dependent differences in adjustments to DST, especially after the spring time change when clocks are advanced by an hour. ${ }^{100}$ Those who were classified as morning types using the MCTQ adjusted more readily to the DST than those who were evening types, who had still failed to re-entrain (adjust their mid-point of sleep on free days or center of gravity of activity) within 3 weeks of the time transition. ${ }^{100}$

A later study also demonstrated that seasonal adaptation in central Europeans was disrupted during the annual transition to DST. ${ }^{101}$ Populations from Estonia $\left(57^{\circ} \mathrm{N}\right.$ to $\left.59^{\circ} \mathrm{N}\right)$, Scotland $\left(59^{\circ} \mathrm{N}\right)$, Germany $\left(48^{\circ} \mathrm{N}\right)$, and Croatia $\left(42^{\circ} \mathrm{N}\right)$ were studied to identify seasonal differences in sleep timing and chronotype during the observance of DST and standard time zone (SZT). ${ }^{101}$ A total of 9,765 participants had their sleep times and chronotype assessed with the MCTQ from 2007 to 2009. Subgroups of each of the populations were assessed either during DST or SZT. Mean chronotype was found to be significantly later during SZT in comparison to the DST in a subgroup of the Estonian population as well as in the German population. They observed no differences in chronotype between SZT and DST in the population from Scotland. As individuals are required to wake up 1 hour earlier during DST and are exposed to longer photoperiods (especially in northern regions), later chronotypes assessed during DST had slightly earlier midpoints of sleep than in the rest of the year and had more irregular sleep times from work to free days. Sleep duration and mid-sleep were analyzed in one of the Estonian subgroups throughout the year, as they experienced the longest day length at summer solstice. It was noted that within this subgroup, those with earlier chronotypes had similar sleep durations and mid-points of sleep throughout the year during periods of both SZT and DST. However, those with later chronotypes showed significant variation in sleep duration during DST. They further observed that with increasing photoperiod from the DST transition in spring to the end of summer, the mean chronotype in Estonia was earlier relative to periods with shorter daylength, from September to February. This implies that assessment of internal time during the DST period may be less reliable than during SZT. The authors concluded that the variation in chronotype across the year was mostly dependent on age, sex, and season of assessment, with season of assessment having the greatest influence. ${ }^{101}$

\section{Conclusion}

Seasonal plasticity of chronotype must confer an adaptive advantage, allowing humans to maximize sleep and activity periods according to the environment. As some humans occupy areas of the planet that experience great variations in light environments, they have evolved mechanisms to ensure circadian entrainment even at low light levels and of varying spectral composition. PER2 gene variants that confer greater circadian light sensitivity have arisen since modern humans migrated from Africa. ${ }^{77}$ Genetic variation in PER2, OPN4, and PER3, as well as differences in eye pigmentation, and endogenous circadian period lead to differences in individual anticipation and responsiveness to seasonal change, and seasonality in humans. Many of these variations are related to geographical area of origin and thus may have had an adaptive advantage for the seasonal variations in those regions. For example, having a longer endogenous period may be in part responsible for the trend observed toward a later chronotype as latitude increases ${ }^{91,92}$ as this may confer the ability to adapt to extremes in seasonal variation.

\section{Acknowledgments}

The work in LCR's lab is funded by grants from the South African National Research Foundation (NRF; IFR180116305742) and the University of cape Town Research Committee (URC).

\section{Disclosure}

NS is the recipient of Organisation for Women in Science for the Developing World (OWSD) Postgraduate Fellowship and a University of Cape Town (UCT) Science Faculty PhD Fellowship. The authors report no other conflicts of interest in this work. 


\section{References}

1. Levandovski R, Sasso E, Hidalgo MP. Chronotype: a review of the advances, limits and applicability of the main instruments used in the literature to assess human phenotype. Trends Psychiatry Psychother. 2013;35(1):3-11.

2. Horne JA, Östberg O. A self-assessment questionnaire to determine morningness-eveningness in human circadian rhythms. Int J Chronobiol. 1976;4:97-110.

3. Goel N, Basner M, Rao H, Dinges DF. Circadian rhythms, sleep deprivation, and human performance. Prog Mol Biol Transl Sci. 2013;119: 155-190.

4. Vitale JA, Roveda E, Montaruli A, et al. Chronotype influences activity circadian rhythm and sleep: differences in sleep quality between weekdays and weekend. Chronobiol Int. 2015;32(3):405-415.

5. Barclay NL, Eley TC, Buysse DJ, Archer SN, Gregory AM, et al. Diurnal preference and sleep quality: same genes? A study of young adult twins. Chronobiol Int. 2010;27(2):278-296.

6. Koskenvuo M, Hublin C, Partinen M, Heikkilä K, Kaprio J, et al. Heritability of diurnal type: a nationwide study of 8753 adult twin pairs. J Sleep Res. 2007;16(2):156-162.

7. Vink JM, Groot AS, Kerkhof GA, Boomsma DI. Genetic analysis of morningness and eveningness. Chronobiol Int. 2001;18(5):809-822.

8. von Schantz M, Taporoski TP, Horimoto ARVR, et al. Distribution and heritability of diurnal preference (chronotype) in a rural Brazilian family-based cohort, the Baependi study. Sci Rep . 2015;5(1):1-6.

9. Adan A, Natale V. Gender differences in morningness-eveningness preference. Chronobiol Int. 2002;19(4):709-720.

10. Kunorozva L, Rae DE, Roden LC. Chronotype distribution in professional rugby players: Evidence for the environment hypothesis? Chronobiol Int. 2017;34(6):762-772.

11. Urbán R, Magyaródi T, Rigó A. Morningness-eveningness, chronotypes and health-impairing behaviors in adolescents. Chronobiol Int. 2011;28(3):238-247.

12. Vitale JA, Bonato M, Galasso L, et al. Sleep quality and high intensity interval training at two different times of day: A crossover study on the influence of the chronotype in male collegiate soccer players. Chronobiol Int. 2017;34(2):260-268.

13. Lucassen EA, Zhao X, et al. Sleep Extension Study Group, et al. Evening chronotype is associated with changes in eating behavior, more sleep apnea, and increased stress hormones in short sleeping obese individuals. PLoS One. 2013;8(3):e56519.

14. Ruiz-Lozano T, Vidal J, de Hollanda A, Canteras M, Garaulet M, Izquierdo-Pulido M. Evening chronotype associates with obesity in severely obese subjects: interaction with CLOCK 3111T/C. Int JObes. 2016;40(10):1550-1557.

15. Yu JH, Yun $\mathrm{CH}$, Ahn JH, et al. Evening chronotype is associated with metabolic disorders and body composition in middle-aged adults. J Clin Endocrinol Metab. 2015;100(4):1494-1502.

16. Rae DE, Stephenson KJ, Roden LC. Factors to consider when assessing diurnal variation in sports performance: the influence of chronotype and habitual training time-of-day. Eur J Appl Physiol. 2015;115(6):1339-1349.

17. Roenneberg T, Wirz-Justice A, Merrow M. Life between Clocks: Daily Temporal Patterns of Human Chronotypes. J Biol Rhythms. 2003;18(1):80-90.

18. Jeong Jeong H, Moon E, Min Park J, Jeong HJ, Park JM, et al. The relationship between chronotype and mood fluctuation in the general population. Psychiatry Res. 2015;229(3):867-871.

19. Gaspar-Barba E, Calati R, Cruz-Fuentes CS, et al. Depressive symptomatology is influenced by chronotypes. J Affect Disord. 2009;119(1-3):100-106.

20. Levandovski R, Dantas G, Fernandes LC, et al. Depression scores associate with chronotype and social jetlag in a rural population. Chronobiol Int. 2011;00(0):1-8.

21. Ahn YM, Chang J, Joo YH, et al. Chronotype distribution in bipolar I disorder and schizophrenia in a Korean sample. Bipolar Disord. 2008;10(2):271-275.
22. Adan A, Almirall H, Horne AH. Horne \& Östberg morningness-eveningness questionnaire: A reduced scale. Pers Individ Dif. 1991;12(3): 241-253.

23. Smith CS, Reilly C, Midkiff K. Evaluation of three circadian rhythm questionnaires with suggestions for an improved measure of morningness. J Appl Psychol. 1989;74(5):728-738.

24. Torsvall L, Åkerstedt T. A diurnal type scale. Construction, consistency and validation in shift work. Scand $J$ Work Environ Health. 1980;6(4):283-290.

26. Roenneberg T, Kuehnle T, Juda M, et al. Epidemiology of the human circadian clock. Sleep Med Rev. 2007;11(6):429-438.

27. Roenneberg T, Merrow M. Entrainment of the human circadian clock. Cold Spring Harb Symp Quant Biol. 2007;72(1):293-299.

28. Takahashi JS. Transcriptional architecture of the mammalian circadian clock. Nat Rev Genet. 2017;18(3):164-179.

29. Shanahan TL, Czeisler CA. Light exposure induces equivalent phase shifts of the endogenous circadian rhythms of circulating plasma melatonin and core body temperature in men. J Clin Endocrinol Metab. 1991;73(2):227-235.

30. Lewy AJ, Bauer VK, Ahmed S, et al. The human phase response curve (PRC) to melatonin is about 12 hours out of phase with the PRC to light. Chronobiol Int. 1998;15(1):71-83.

31. Czeisler CA, Kronauer RE, Allan JS, et al. Bright light induction of strong (type 0) resetting of the human circadian pacemaker. Science. 1989;244(4910):1328-1333.

32. Roenneberg T, Daan S, Merrow M. The art of entrainment. J Biol Rhythms. 2003;18(3):183-194.

33. Ralph MR, Foster RG, Davis FC, Menaker M. Transplanted suprachiasmatic nucleus determines circadian period. Science. 1990;247(4945):975-978.

34. Yoo SH, Yamazaki S, Lowrey PL, et al. PERIOD2::LUCIFERASE real-time reporting of circadian dynamics reveals persistent circadian oscillations in mouse peripheral tissues. Proc Natl Acad Sci U S A. 2004;101(15):5339-5346.

35. Mohawk JA, Green CB, Takahashi JS. Central and peripheral circadian clocks in mammals. Annu Rev Neurosci. 2012;35(1):445-462.

36. Chen SK, Badea TC, Hattar S. Photoentrainment and pupillary light reflex are mediated by distinct populations of ipRGCs. Nature. 2011;476(7358):92-95.

37. Provencio I, Rodriguez IR, Jiang G, Hayes WP, Moreira EF, Rollag MD. A novel human opsin in the inner retina. JNeurosci. 2000;20(2):600-605.

38. Hughes S, Jagannath A, Hankins MW, et al. Photic regulation of clock systems. Methods Enzymol. 2015;552:125-143.

39. Berson DM, Dunn FA, Takao M. Phototransduction by retinal ganglion cells that set the circadian clock. Science. 2002;295(5557): 1070-1073.

40. Panda S, Nayak SK, Campo B, Walker JR, Hogenesch JB, Jegla T. Illumination of the Melanopsin Signaling Pathway. Science. 2005;307(5709):600-604.

41. Takahashi JS, Decoursey PJ, Bauman L, Menaker M, et al. Spectral sensitivity of a novel photoreceptive system mediating entrainment of mammalian circadian rhythms. Nature. 1984;308(5955):186-188.

42. Brainard GC, Hanifin JP, Greeson JM, et al. Action spectrum for melatonin regulation in humans: evidence for a novel circadian photoreceptor. J Neurosci. 2001;21(16):6405-6412.

43. Minors DS, Waterhouse JM, Wirz-Justice A. A human phase-response curve to light. Neurosci Lett. 1991;133(1):36-40.

44. Czeisler CA, Allan JS, Strogatz SH, et al. Bright light resets the human circadian pacemaker independent of the timing of the sleep-wake cycle. Science. 1986;233(4764):667-671.

45. Duffy JF, Kronauer RE, Czeisler CA. Phase-shifting human circadian rhythms: influence of sleep timing, social contact and light exposure. J Physiol. 1996;495 (Pt 1):289-297.

46. Duffy JF, Dijk DJ. Getting through to circadian oscillators: why use constant routines? J Biol Rhythms. 2002;17(1):4-13.

47. Duffy JF, Rimmer DW, Czeisler CA. Association of intrinsic circadian period with morningness-eveningness, usual wake time, and circadian phase. Behav Neurosci. 2001;115(4):895-899. 
48. Kerkhof GA, van Dongen HP. Morning-type and evening-type individuals differ in the phase position of their endogenous circadian oscillator. Neurosci Lett. 1996;218(3):153-156.

49. Duffy JK, Dijk DJ, Hall EF, et al. Relationship of Endogenous circadian melatonin and. temperature rhythms to self-reported preference for morning or evening activity in young and older people. $J$ Investig Med. 1999;47(3):141-150.

50. Trenberth KE. What are the Seasons? Bull Am Meteorol Soc. 1983;64(11):1276-1282.

51. Hébert M, Dumont M, Paquet J. Seasonal and diurnal patterns of human illumination under natural conditions. Chronobiol Int. 1998;15(1):59-70.

52. Wehr TA. The durations of human melatonin secretion and sleep respond to changes in daylength (photoperiod. J Clin Endocrinol Metab. 1991;73(6):1276-1280.

53. Wehr TA, Moul DE, Barbato G, et al. Conservation of photoperiodresponsive mechanisms in humans. Am J Physiol Regul Integr Comp Physiol. 1993;265(4):R846-R857.

54. Illnerová $H$, Zvolsky $P$, Vanĕcek $J$. The circadian rhythm in plasma melatonin concentration of the urbanized man: the effect of summer and winter time. Brain Res. 1985;328(1):186-189.

55. Vondrašová D, Hájek I, Illnerová H. Exposure to long summer days affects the human melatonin and cortisol rhythms. Brain Res. 1997;759(1):166-170.

56. Vondrašová-Jelínková D, Hájek I, Illnerová H. Adjustment of the human melatonin and cortisol rhythms to shortening of the natural summer photoperiod. Brain Res. 1999;816(1):249-253\&.

57. Adamsson M, Laike T, Morita T. Annual variation in daily light exposure and circadian change of melatonin and cortisol concentrations at a northern latitude with large seasonal differences in photoperiod length. J Physiol Anthropol. 2017;36(1):6.

58. Yoneyama S, Hashimoto S, Honma K. Seasonal changes of human circadian rhythms in Antarctica. Am J Physiol. 1999;277(4 Pt 2):R1091-R1097.

59. Thorne HC, Jones KH, Peters SP, Archer SN, Dijk D-J, et al. Daily and seasonal variation in the spectral composition of light exposure in humans. Chronobiol Int. 2009;26(5):854-866.

60. Higuchi S, Motohashi Y, Ishibashi K, Maeda T. Influence of eye colors of Caucasians and Asians on suppression of melatonin secretion by light. Am J Physiol Regul Integr Comp Physiol. 2007;292(6):R2352-R2356.

61. van der Meijden WP, van Someren JL, Te Lindert BH, et al. Individual differences in sleep timing relate to melanopsin-based phototransduction in healthy adolescents and young adults. Sleep 2016;39(6):1305-1310.

62. Glickman G, Webb IC, Elliott JA, et al. Photic sensitivity for circadian response to light varies with photoperiod. J Biol Rhythms. 2012;27(4):308-318.

63. Thompson C, Stinson D, Smith A. Seasonal affective disorder and season-dependent abnormalities of melatonin suppression by light. Lancet. 1990;336(8717):703-706.

64. Vandewalle G, Hébert M, Beaulieu C, et al. Abnormal hypothalamic response to light in seasonal affective disorder. Biol Psychiatry. 2011;70(10):954-961.

65. Hébert M, Martin SK, Lee C, Eastman CI. The effects of prior light history on the suppression of melatonin by light in humans. J Pineal Res. 2002;33(4):198-203.

66. Smith KA, Schoen MW, Czeisler CA. Adaptation of human pineal melatonin suppression by recent photic history. J Clin Endocrinol Metab. 2004;89(7):3610-3614.

67. Higuchi S, Motohashi Y, Ishibashi K, Maeda T. Less exposure to daily ambient light in winter increases sensitivity of melatonin to light suppression. Chronobiol Int. 2007b;24(1):31-43.

68. Chang AM, Scheer FA, Czeisler CA. The human circadian system adapts to prior photic history. J Physiol. 2011;589(Pt 5):1095-1102.

69. Smith MR, Burgess HJ, Fogg LF, Eastman CI. Racial differences in the human endogenous circadian period. PLoS One. 2009;4(6):e6014.
70. Eastman CI, Suh C, Tomaka VA, Crowley SJ. Circadian rhythm phase shifts and endogenous free-running circadian period differ between African-Americans and European-Americans. Sci Rep. 2015;5(1):8381.

71. Archer SN, Robilliard DL, Skene DJ, et al. A length polymorphism in the circadian clock gene Per3 is linked to delayed sleep phase syndrome and extreme diurnal preference. Sleep. 2003;26(4):413-415.

72. Kunorozva L, Stephenson KJ, Rae DE, Roden LC. Chronotype and $P E R I O D 3$ variable number tandem repeat polymorphism in individual sports athletes. Chronobiol Int. 2012;29(8):1004-1010.

73. Chellappa SL, Viola AU, Schmidt C, et al. Human melatonin and alerting response to blue-enriched light depend on a polymorphism in the clock gene PER3. J Clin Endocrinol Metab. 2012;97(3):E433-E437.

74. Barclay NL, Eley TC, Mill J, et al. Sleep quality and diurnal preference in a sample of young adults: Associations with $5 H T T L P R, P E R 3$, and CLOCK 3111. American Journal of Medical Genetics Prt B: Neuropsychiatric Genetics. 2011;156(6):681-690.

75. Goel N, Banks S, Mignot E, Dinges DF. PER3 polymorphism predicts cumulative sleep homeostatic but not neurobehavioral changes to chronic partial sleep deprivation. PLoS One. 2009;4(6):e5874.

76. Osland TM, Bjorvatn BR, Steen VM, Pallesen S. Association study of a variable-number tandem repeat polymorphism in the clock gene PERIOD3 and chronotype in Norwegian university students. Chronobiol Int. 2011;28(9):764-770.

77. Akiyama T, Katsumura T, Nakagome S, et al. An ancestral haplotype of the human PERIOD2 gene associates with reduced sensitivity to lightinduced melatonin suppression. PLoS One. 2017;12(6):e0178373.

78. Cruciani F, Trombetta B, Labuda D, et al. Genetic diversity patterns at the human clock gene period 2 are suggestive of population-specific positive selection. Eur J Hum Genet. 2008;16(12):1526-1534.

79. Roecklein KA, Rohan KJ, Duncan WC, et al. A missense variant (P10L) of the melanopsin (OPN4) gene in seasonal affective disorder. JAffect Disord. 2009;114(1-3):279-285.

80. Roecklein KA, Wong PM, Franzen PL, et al. Melanopsin gene variations interact with season to predict sleep onset and chronotype. Chronobiol Int. 2012;29(8):1036-1047.

81. Higuchi S, Hida A, Tsujimura SI, Mishima K, Yasukouchi A, Lee SI, et al. Melanopsin gene polymorphism I394T is associated with pupillary light responses in a dose-dependent manner. PLoS One. 2013;8(3):e60310.

82. Lee SI, Hida A, Kitamura S, Mishima K, Higuchi S. Association between the melanopsin gene polymorphism OPN4*Ile394Thr and sleep/wake timing in Japanese university students. J Physiol Anthropol. 2014;33(1):9.

83. Bronson FH. Are humans seasonally photoperiodic? J Biol Rhythms. 2004;19(3):180-192.

84. Roenneberg T. The decline in human seasonality. J Biol Rhythms. 2004;19(3):193-195.

85. Roenneberg T, Aschoff J. Annual rhythm of human reproduction: II Environmental correlations. J Biol Rhythms. 1990;5(3):217-239.

86. Yetish G, Kaplan H, Gurven M, et al. Natural sleep and its seasonal variations in three pre-industrial societies. Curr Biol. 2015;25(21):2862-2868.

87. Beale AD, Pedrazzoli M, Gonçalves BDSB, et al. Comparison between an African town and a neighbouring village shows delayed, but not decreased, sleep during the early stages of urbanisation. Sci Rep. 2017;7(1):5697.

88. Wright KP, McHill AW, Birks BR, Griffin BR, Rusterholz T, Chinoy ED. Entrainment of the human circadian clock to the natural light-dark cycle. Curr Biol. 2013;23(16):1554-1558.

89. Stothard ER, McHill AW, Depner CM, et al. Circadian entrainment to the natural light-dark cycle across seasons and the weekend. Current Biology. 2017;27(4):508-513.

90. Leocadio-Miguel MA, Louzada FM, Duarte LL, et al. Latitudinal cline of chronotype. Sci Rep. 2017;7(1):5437.

91. Borisenkov MF. Human chronotypes in the North. Hum Physiol. 2010;36(3):348-352.

92. Randler C. Morningness-eveningness comparison in adolescents from different countries around the world. Chronobiol Int. 2008;25(6):1017-1028. 
93. Borisenkov MF, Kosova AL, Kasyanova ON. Impact of perinatal photoperiod on the chronotype of 11-18-year-olds. Chronobiol Int. 2012;29(3):305-310.

94. Natale V, di Milia L. Season of birth and morningness: comparison between the northern and southern hemispheres. Chronobiol Int. 2011;28(8):727-730.

95. Mongrain V, Paquet J, Dumont M. Contribution of the photoperiod at birth to the association between season of birth and diurnal preference. Neurosci Lett. 2006;406(1-2):113-116.

96. Vollmer C, Randler C, di Milia L. Further Evidence for the Influence of Photoperiod at Birth on Chronotype in a Sample of German Adolescents. Chronobiol Int. 2012;29(10):1345-1351.
97. Natale V, Adan A. Season of birth modulates morningness-eveningness preference in humans. Neurosci Lett. 1999;274(2):139-141.

98. Roenneberg T, Kumar CJ, Merrow M. The human circadian clock entrains to sun time. Curr Biol. 2007;17(2):R44-R45.

99. Shawa N, Roden LC. Chronotype of South African adults is affected by solar entrainment. Chronobiol Int. 2016;33(3):315-323.

100. Kantermann T, Juda M, Merrow M, Roenneberg T. The human circadian clock's seasonal adjustment is disrupted by daylight saving time. Current Biology. 2007;17(22):1996-2000.

101. Allebrandt KV, Teder-Laving M, Kantermann T, et al. Chronotype and sleep duration: The influence of season of assessment. Chronobiol Int. 2014;31(5):731-740.

\section{Publish your work in this journal}

Nature and Science of Sleep is an international, peer-reviewed, open access journal covering all aspects of sleep science and sleep medicine, including the neurophysiology and functions of sleep, the genetics of sleep, sleep and society, biological rhythms, dreaming, sleep disorders and therapy, and strategies to optimize healthy sleep. The manuscript
Dovepress

management system is completely online and includes a very quick and fair peer-review system, which is all easy to use. Visit http://www dovepress.com/testimonials.php to read real quotes from published authors. 